\section{Commentary: Hear no evil, see no evil-except with 4-dimensional cardiac computed tomography!}

\author{
Torsten Doenst, $\mathrm{MD}, \mathrm{PhD},{ }^{\mathrm{a}}$ and \\ Mario F. Gaudino, MD, PhD, MSCE ${ }^{\mathrm{b}}$
}

Surgery of the aortic root entails complex procedures that require operative experience and skill. Given this complexity, long-term complications may be expected, but in general events such as pseudoaneurysm formation at the suture lines and coronary ostial stenoses have been considered as rare and ascribed to specific individual factors associated with the patient, the surgeon, or both. ${ }^{1,2}$ Clearly, no surgeon is happy to see or hear concerns regarding his or her operative result. Thus far, we "saw no evil" using classic tools of follow-up.

In recent years, noninvasive cardiac imaging has made tremendous advances. In coronary artery disease, cardiac computed tomography (CT) has emerged as viable alternative to conventional invasive coronary imaging. It has received preferred recommendations for making the primary diagnosis of coronary artery disease by the British guidelines ${ }^{3}$ and has mastered the first comparative analysis study addressing decision-making for invasive therapy of triple-vessel disease. ${ }^{4}$ In transcatheter aortic valve implantation, it was 4-dimensional cardiac CT (4DCT) that identified thrombotic hypoattenuated leaflet motion and thickening, which is often asymptomatic but has generated tremendous concern and discussion. ${ }^{5-7}$

In this issue of the Journal, Dagnegard and colleagues ${ }^{8}$ used 4DCT on 253 patients having received aortic root replacement in 2 renown centers between 1999 and 2017. The authors made an alarming observation. In one half of

\footnotetext{
From the ${ }^{\mathrm{a} D e p a r t m e n t}$ of Cardiothoracic Surgery, Friedrich-Schiller-University Jena, University Hospital, Jena, Germany; and ${ }^{\mathrm{b}}$ Department of Cardiothoracic Surgery at New York Presbyterian, Weill Cornell Medical Center, New York, NY.

Disclosures: The authors reported no conflicts of interest.

The Journal policy requires editors and reviewers to disclose conflicts of interest and to decline handling or reviewing manuscripts for which they may have a conflict of interest. The editors and reviewers of this article have no conflicts of interest.

Received for publication May 5, 2021; revisions received May 5, 2021; accepted for publication May 7, 2021; available ahead of print May 12, 2021.

Address for reprints: Mario F. Gaudino, MD, PhD, MSCE, Department of Cardiothoracic Surgery, Weill Cornell Medicine, 525 E 68th St, New York, NY 10065 (E-mail: mfg9004@med.cornell.edu).

J Thorac Cardiovasc Surg 2023;165:1298-9

$0022-5223 / \$ 36.00$

Copyright (c) 2021 by The American Association for Thoracic Surgery

https://doi.org/10.1016/j.jtcvs.2021.05.012
}

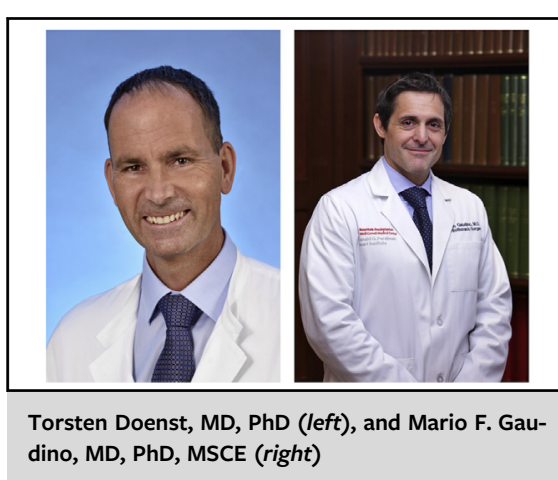

CENTRAL MESSAGE

Four-dimensional cardiac computed tomography is a powerful imaging tool for cardiac surgery. It opens our eyes to better follow our patients. A prime example may be patients with root replacements.

their patients, 4DCT revealed asymptomatic but potentially devastating complications, which also caused a significant increase in reoperations. Ostial stenoses or hypoattenuated leaflet thickening was present in every fifth patient, and a pseudoaneurysm was observed in $12 \%$.

These results raise serious concern and certainly require further investigation. Are the findings primarily due to the suggested differences in diagnostic power between 4DCT and classic transthoracic echocardiography? The authors already discussed potential alternatives, but at least 2 observations are additionally worth considering. First, a recent randomized controlled trial comparing freestyle with homograft root replacements presents excellent 20-year results for both groups with life expectancies similar to the general population. ${ }^{9}$ A $50 \%$ complication rate may not have allowed such outstanding results. Second, the rate of pseudoaneurysms in the series by Dagnegard and colleagues appears high and one would, at the illustrated rate and dimension, expect to detect it even with transthoracic echocardiography. Could lack of geometric precision at root reconstruction be the responsible? It gives rise to paravalvular leaks in stented prostheses ${ }^{2}$ and may give rise to pseudoaneurysms due to suture dehiscence in root replacement. Such geometric distortions may also give rise to cusp deformation and irregular movement, potentially leading to 
leaflet thrombosis, which was also frequently observed in the authors' data set.

In any case, the authors need to be congratulated because the application of 4DCT in the subgroup of patients having received root replacement is definitely a step in the right direction. We, as surgeons, cannot close our eyes but need to embrace the new powerful imaging to prevent and/or treat potential evil.

\section{References}

1. Atik FA, Navia JL, Svensson LG, Vega PR, Feng J, Brizzio ME, et al. Surgical treatment of pseudoaneurysm of the thoracic aorta. J Thorac Cardiovasc Surg. 2006;132:379-85.

2. Matteucci M, Ferrarese S, Cantore C, Massimi G, Facetti S, Mantovani V, et al. Early aortic paravalvular leak after conventional cardiac valve surgery: a singlecenter experience. Ann Thorac Surg. 2020;109:517-25.

3. Moss AJ, Williams MC, Newby DE, Nicol ED. The updated NICE guidelines: cardiac CT as the first-line test for coronary artery disease. Curr Cardiovasc Imaging Rep. 2017;10:15.
4. Sonck J, Miyazaki Y, Collet C, Onuma Y, Asano T, Takahashi K, et al. Feasibility of planning coronary artery bypass grafting based only on coronary computed tomography angiography and CT-derived fractional flow reserve: a pilot survey of the surgeons involved in the randomized SYNTAX III revolution trial. Interact Cardiovasc Thorac Surg. 2019;ivz046.

5. Laschinger JC, Wu C, Ibrahim NG, Shuren JE. Reduced leaflet motion in bioprosthetic aortic valves-the FDA perspective. N Engl J Med. 2015;373: 1996-8.

6. Makkar RR, Blanke P, Leipsic J, Thourani V, Chakravarty T, Brown D, et al. Subclinical leaflet thrombosis in transcatheter and surgical bioprosthetic valves: PARTNER 3 cardiac computed tomography substudy. J Am Coll Cardiol. 2020; 75:3003-15.

7. Makkar RR, Fontana G, Jilaihawi H, Chakravarty T, Kofoed KF, De Backer O et al. Possible subclinical leaflet thrombosis in bioprosthetic aortic valves. $N$ Engl J Med. 2015;373:2015-24.

8. Dagnegard HSH, Sigvardsen PE, Ihlemann N, Kofoed KF, El-Hamamsy I, Bekke K, et al. Structural abnormalities after aortic root replacement with stentless xenograft. J Thorac Cardiovasc Surg. 2023;165:1285-97.e6.

9. Melina G, De Robertis F, Gaer JA, Angeloni E, El-Hamamsy I, Bahrami T, et al Long-term survival after xenograft versus homograft aortic root replacement: results from a prospective randomized trial. J Thorac Cardiovasc Surg. 2019;161: $57-65$.

\section{Commentary: Freestyle root replacement is not free and long-term radiographic surveillance should be in style}

\section{Charles M. Wojnarski, MD, MS}

Holmgren-Dagnegard and colleagues ${ }^{1}$ present a crosssectional, radiographic study of a large population of patients who had undergone stentless xenograft (Freestyle; Medtronic Incorporated, Minneapolis, Minn) aortic root replacement at 2 institutions (Rigshospitalet, University Hospital of Copenhagen and Montreal Heart Institute, University of Montreal). ${ }^{1}$ They performed transthoracic echocardiography and contrast-enhanced,

\footnotetext{
From the Division of Cardiovascular and Thoracic Surgery, Department of Surgery, Duke University Medical Center, Durham, NC.

Disclosures: The author reported no conflicts of interest.

The Journal policy requires editors and reviewers to disclose conflicts of interest and to decline handling or reviewing manuscripts for which they may have a conflict of interest. The editors and reviewers of this article have no conflicts of interest.

Received for publication May 23, 2021; revisions received May 23, 2021; accepted for publication May 26, 2021; available ahead of print June 1, 2021.

Address for reprints: Charles M. Wojnarski, MD, MS, Division of Cardiovascular and Thoracic Surgery, Department of Surgery, Duke University Medical Center, 2301

Erwin Rd, Durham, NC 27710 (E-mail: charles.wojnarski@duke.edu).

J Thorac Cardiovasc Surg 2023;165:1299-300

$0022-5223 / \$ 36.00$

Copyright (c) 2021 by The American Association for Thoracic Surgery

https://doi.org/10.1016/j.jtcvs.2021.05.041
}

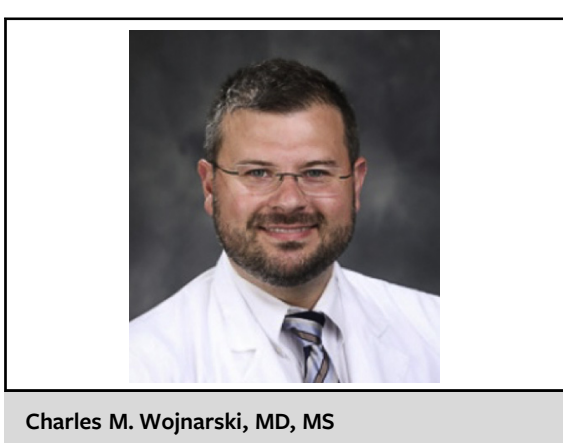

CENTRAL MESSAGE

After Freestyle root replacement, incidence of pseudoaneurysm, ostial coronary stenosis, and leaflet degeneration is not insignificant and may be identified with routine CT follow-up.

echocardiography-gated 4-dimensional cardiac computed tomography (4DCT) on all included patients $(\mathrm{N}=253)$ and present data on the prevalence of various established, long-term anatomic abnormalities that can occur after aortic root replacement with this valve conduit. Furthermore, the authors present the clinical implications of the findings by 